\title{
BMJ
}

\section{Cancer morbidity in British military veterans included in chemical warfare agent experiments at Porton Down: cohort study}

\begin{abstract}
L M Carpenter, reader in statistical epidemiology, ${ }^{1} \mathrm{~L}$ Linsell, medical statistician, ${ }^{1}$ C Brooks, data manager, ${ }^{1}$ T J Keegan, research fellow, ${ }^{1} \mathrm{~T}$ Langdon, assistant data manager, ${ }^{1}$ P Doyle, professor of epidemiology, ${ }^{2}$ N E S Maconochie, senior lecturer in epidemiology and medical statistics, ${ }^{2}$ T Fletcher, senior lecturer in environmental epidemiology, ${ }^{3} \mathrm{M}$ J Nieuwenhuijsen, research professor in environmental epidemiology ${ }^{4}$, visiting professor, ${ }^{5} \mathrm{~V}$ Beral, professor and director, ${ }^{6} \mathrm{~K}$ M Venables, reader in occupational medicine ${ }^{1}$
\end{abstract}

Department of Public Health University of Oxford, Oxford OX3 7LF

${ }^{2}$ Department of Epidemiology and Population Health, London School of Hygiene and Tropical Medicine, London

${ }^{3}$ Department of Public Health and Policy, London School of Hygiene and Tropical Medicine

${ }^{4}$ Center for Research in Environmental Epidemiology, IMIM and CIBERESP, 08003 Barcelona, Spain

${ }^{5}$ Division of Epidemiology, Public Health and Primary Care, Imperial College, London

${ }^{6}$ Cancer Epidemiology Unit, University of Oxford

Correspondence to: L M Carpenter lucy.carpenter@dphpc.ox.ac.uk;K $M$ Venables

kate.venables@dphpc.ox.ac.uk

Cite this as: $B M J$ J 2009;338:b655 doi:10.1136/bmj.b655

\section{ABSTRACT}

Objective To determine cancer morbidity in members of the armed forces who took part in tests of chemical warfare agents from 1941 to 1989.

Design Historical cohort study, with cohort members followed up to December 2004.

Data source Archive of UK government research facility at Porton Down, UK military personnel records, and national death and cancer records.

Participants All veterans included in the cohort study of mortality, excluding those known to have died or been lost to follow-up before 1 January 1971 when the UK cancer registration system commenced. 17013 male members of the UK armed forces who took part in tests (Porton Down veterans) and a similar group of 16520 who did not (nonPorton Down veterans).

Main outcome measures Cancer morbidity in each group of veterans; rate ratios, with $95 \%$ confidence intervals, adjusted for age group and calendar period.

Results 3457 cancers were reported in the Porton Down veterans compared with 3380 cancers in the non-Porton Down veterans. While overall cancer morbidity was the same in both groups (rate ratio 1.00, 95\% confidence interval 0.95 to 1.05$)$, Porton Down veterans had higher rates of ill defined malignant neoplasms $(1.12,1.02$ to $1.22)$, in situ neoplasms $(1.45,1.06$ to 2.00$)$, and those of uncertain or unknown behaviour (1.32, 1.01 to 1.73).

Conclusion Overall cancer morbidity in Porton Down veterans was no different from that in non-Porton Down veterans.

\section{INTRODUCTION}

After the first world war, research conducted at the chemical defence establishment at Porton Down included a "human volunteer programme" and members of the armed forces took part in experiments studying the potential impact of chemical agents on military capability and the effectiveness of protective measures. ${ }^{12}$ Between 1941 and 1989, over 18000 members of the armed forces were recorded as having taken part in this programme. Over $50 \%$ of these veterans were recorded as taking part in tests involving chemicals that are known or probable human carcinogens, the most common being dermal exposures to sulphur mustard. ${ }^{3}$ While their overall cancer mortality was similar to that of veterans who did not take part in tests at Porton Down, ${ }^{4}$ past exposure to these chemicals might have affected their risk of developing common cancers with relatively good survival such as certain skin cancers. We report here on cancer morbidity in Porton Down veterans by studying cancers reported for the period from 1971, when the UK cancer registration system commenced, to 2004 .

\section{METHODS}

Information provided here focuses on aspects relevant to cancer morbidity. More details of the methods used are provided elsewhere. ${ }^{4}$

\section{Study population}

We considered for inclusion all veterans included in the cohort study of mortality. ${ }^{4}$ Porton Down veterans were all male members of the British armed forces recorded as having participated in tests between 1 April 1941 and 31 December 1989, while non-Porton Down veterans were other similar members of the armed forces not recorded as having taken part in tests at Porton Down. ${ }^{4}$ We excluded veterans known to have died or been lost to follow-up before 1 January 1971.

\section{Follow-up}

We obtained death certificates, notifications of emigrations, and data on cancers registered since 1 January 1971 from the National Health Service central registers. ${ }^{4}$ Each condition listed on death certificates as causing or contributing to death was coded by the Office for National Statistics according to ICD-10 (international classification of diseases, 10th revision). Cancer registration data for all cancers registered on or 
after 1 January 1971 were provided electronically and included date of diagnosis and cancer site or type coded according to the ICD coding system at the time of registration (ICD-8, 9, or 10). The research team recoded ICD-8 and ICD-9 codes to ICD-10 codes.
Classification of chemical exposures

We used contemporaneous experimental records of tests carried out as part of the "human volunteer programme" in the Porton Down historical archive to retrospectively assess exposure. ${ }^{35}$ Data abstraction

Any neoplasm
Any malignant neoplasm
Upper aerodigestive
Oesophagus
Stomach
Intestine and rectum
Pancreas
Trachea, bronchus, and lung
Melanoma of skin
Other skin
Prostate
Bladder
Other urinary tract
Brain and other central nervous system
All leukaemias
Other lymphatic and haematopoietic
All other primary
IIl defined, secondary, or unspecified
Any in situ neoplasm
Any benign neoplasm
Any neoplasm of uncertain or
unknown behaviour

Any vesicant

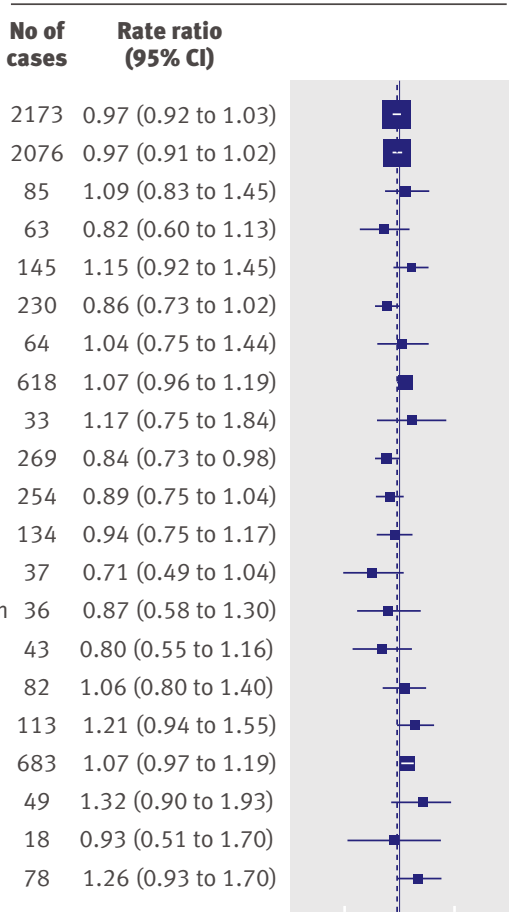

Any Lewisite

Any neoplasm
Any malignant neoplasm
Upper aerodigestive
Oesophagus
Stomach
Intestine and rectum
Pancreas
Trachea, bronchus, and lung
Melanoma of skin
Other skin
Prostate
Bladder
Other urinary tract
Brain and other central nervous system
All leukaemias
Other lymphatic and haematopoietic
All other primary
IIl defined, secondary, or unspecified
Any in situ neoplasm
Any benign neoplasm
Any neoplasm of uncertain or
unknown behaviour

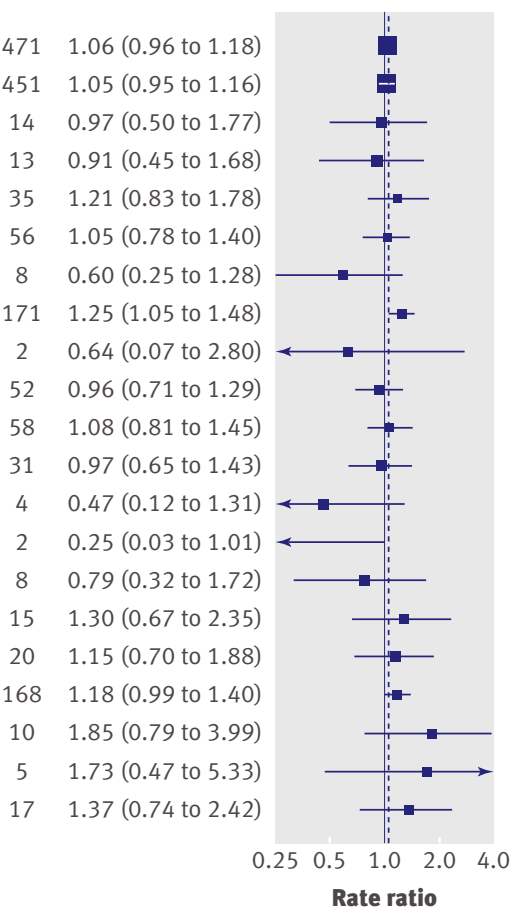

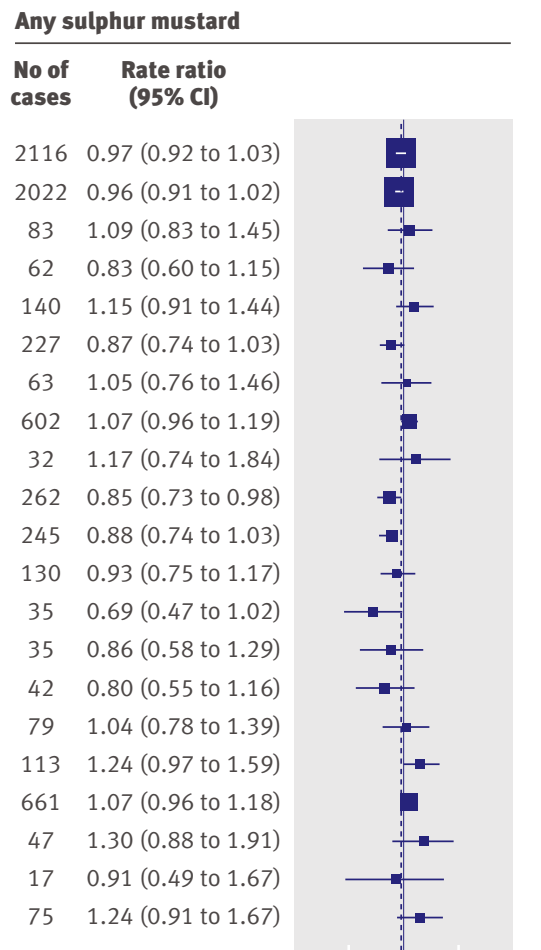

Any nitrogen mustard

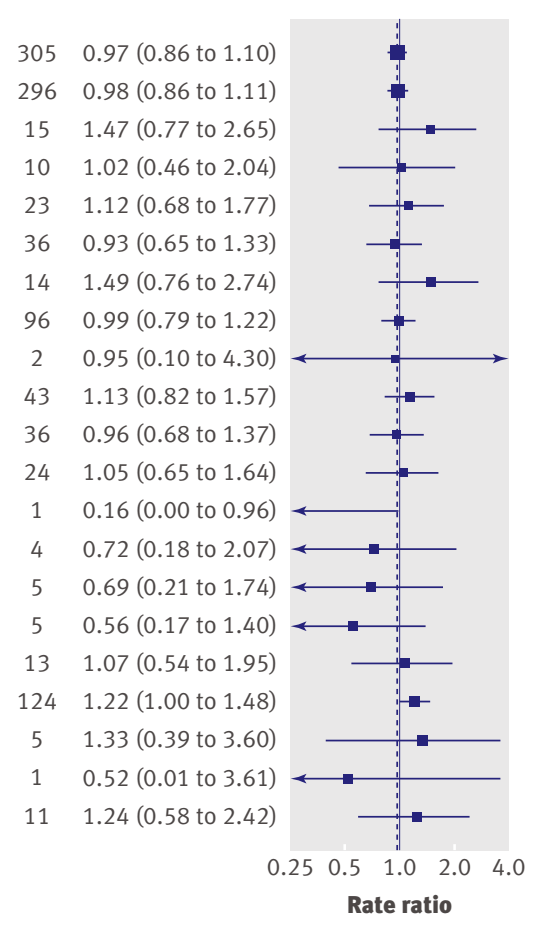

Fig $1 \mid$ Rate ratios for selected cancer sites or types in Porton Down veterans included in tests involving vesicants relative to all nonPorton Down veterans, adjusted for age group and calendar period. Rate ratio estimates are represented by box with size inversely proportional to variance. Vertical dotted line shows the estimate for any neoplasm 
involved linking, when possible, each test to an individual veteran and the classification of that test as involving a chemical or not. The type of chemical was recorded as being a vesicant (blistering agent), a nerve agent, or other chemical. There were eight specific chemicals for which there were records of at least 1000 Porton Down veterans having been tested: three vesicants (sulphur mustard, Lewisite, and nitrogen mustard), one nerve agent (sarin), two lachrymators (CS and CR), and two anti-nerve agent pharmaceutical chemicals (pralidoxime and atropine). Two of these

Table 1| Characteristics of 17013 Porton Down veterans and 16520 non-Porton Down veterans contributing to cancer morbidity analyses. Figures are numbers (percentages) of veterans

\begin{tabular}{|c|c|c|}
\hline Characteristic & $\begin{array}{l}\text { Porton Down } \\
\text { veterans }\end{array}$ & $\begin{array}{l}\text { Non-Porton Down } \\
\text { veterans }\end{array}$ \\
\hline \multicolumn{3}{|l|}{ Service at enlistment: } \\
\hline Army & $10348(60.8)$ & $9976(60.4)$ \\
\hline Air force & 3924 (23.1) & 3885 (23.5) \\
\hline Navy (and marines) & $2741(16.1)$ & $2659(16.1)$ \\
\hline \multicolumn{3}{|l|}{ Decade of birth: } \\
\hline Before 1920 & $2988(17.6)$ & 3125 (18.9) \\
\hline $1920 s$ & 3168 (18.6) & $2960(17.9)$ \\
\hline $1930 \mathrm{~s}$ & $5942(34.9)$ & $5833(35.3)$ \\
\hline 1940 s or later & 4915 (28.9) & $4602(27.9)$ \\
\hline \multicolumn{3}{|l|}{ Place of birth: } \\
\hline England & $13440(79.9)$ & $12974(79.2)$ \\
\hline Wales & $846(5.0)$ & $861(5.3)$ \\
\hline Scotland & $1607(9.6)$ & $1673(10.2)$ \\
\hline Other & $908(5.4)$ & $864(5.3)$ \\
\hline \multicolumn{3}{|l|}{ Age (years) at enlistment: } \\
\hline$\ll 16$ & $1207(7.1)$ & $1192(7.2)$ \\
\hline $16-<18$ & $4831(28.6)$ & $4178(25.3)$ \\
\hline $18-<20$ & $6104(36.1)$ & $5896(35.7)$ \\
\hline $20-<22$ & $2081(12.3)$ & $2242(13.6)$ \\
\hline$\geq 22$ & $2688(15.9)$ & $3002(18.2)$ \\
\hline \multicolumn{3}{|l|}{ Period at enlistment*: } \\
\hline Before second world war & $749(4.4)$ & $706(4.3)$ \\
\hline During second world war & $4448(26.3)$ & $4347(26.3)$ \\
\hline After second world war & $7571(44.8)$ & $7462(45.2)$ \\
\hline After national service & $4143(24.5)$ & 3995 (24.2) \\
\hline \multicolumn{3}{|l|}{ Total duration of service†: } \\
\hline$<2$ & $397(2.4)$ & $2705(16.4)$ \\
\hline $2-\ll 3$ & 2761 (16.5) & 3304 (20.0) \\
\hline $3-<4$ & 2499 (14.9) & $2480(15.0)$ \\
\hline $5-<10$ & 6355 (37.9) & $5040(30.5)$ \\
\hline$\geq 10$ & $4755(28.4)$ & $2980(18.1)$ \\
\hline \multicolumn{3}{|c|}{ Vital state at 31 December 2004: } \\
\hline Alive & $10396(61.1)$ & $10222(61.9)$ \\
\hline Deceased & $6510(38.3)$ & $6197(37.5)$ \\
\hline \multicolumn{3}{|l|}{ Follow-up censored at: } \\
\hline Discharge from services & $41(0.2)$ & $30(0.2)$ \\
\hline Emigration & $17(0.1)$ & $20(0.1)$ \\
\hline Other & $49(0.3)$ & $51(0.3)$ \\
\hline
\end{tabular}

*Second world war dates taken as 1 September 1939 to 30 April 1945 national service dates taken as 1 May 1945 to 31 December 1960. †Includes 148 Porton Down veterans, and 132 non-Porton Down veterans still serving at time of data abstraction.
Table 2 | Exposure data abstracted in 17013 Porton Down veterans contributing to cancer morbidity analyses

\begin{tabular}{|c|c|}
\hline & No (\%) of veterans \\
\hline \multicolumn{2}{|l|}{ No of tests: } \\
\hline 1 & 2010 (11.8) \\
\hline $2-5$ & $3844(22.6)$ \\
\hline $6-9$ & $3523(20.7)$ \\
\hline $10-14$ & $2806(16.5)$ \\
\hline$\geq 15$ & $3910(23.0)$ \\
\hline None & $920(5.4)$ \\
\hline \multicolumn{2}{|l|}{ Decade of first test*: } \\
\hline $1940 \mathrm{~s}$ & $5437(32.0)$ \\
\hline $1950 \mathrm{~s}$ & $5933(34.9)$ \\
\hline $1960 \mathrm{~s}$ & $2230(13.1)$ \\
\hline 1970s & 1964 (11.5) \\
\hline $1980 \mathrm{~s}$ & $1449(8.5)$ \\
\hline \multicolumn{2}{|l|}{ No of chemical testst: } \\
\hline$\geq 1$ & $15481(96.2)$ \\
\hline None & $612(3.8)$ \\
\hline \multicolumn{2}{|l|}{ Type of chemical test†: } \\
\hline \multicolumn{2}{|l|}{ Vesicant: } \\
\hline Any & $9473(58.9)$ \\
\hline Sulphur mustard $\ddagger$ & $9232(57.4)$ \\
\hline Lewisite & $1437(8.9)$ \\
\hline Nitrogen mustard & $971(6.0)$ \\
\hline \multicolumn{2}{|l|}{ Nerve agent: } \\
\hline Any & $3488(21.7)$ \\
\hline Sarin & $2896(18.0)$ \\
\hline \multicolumn{2}{|l|}{ Other chemical: } \\
\hline Any & $11292(70.2)$ \\
\hline CS & $1315(8.2)$ \\
\hline CR & $1172(7.3)$ \\
\hline Pralidoxime & $1690(10.5)$ \\
\hline Atropine & $1552(9.6)$ \\
\hline Benzene & $812(5.0)$ \\
\hline
\end{tabular}

*Date of first visit for those with no test data.

†Includes 16039 veterans for whom type of test could be determined. flncludes mustard sensitivity tests.

chemicals have been classified by the International Agency for Research on Cancer (IARC) as either a known (sulphur mustard and cancer of the upper and lower respiratory tract) or probable (nitrogen mustard and squamous cell carcinoma of the skin) human carcinogen. ${ }^{6}$ We also considered benzene, a chemical classified by IARC as a leukaemogen ${ }^{6}$ and used as a diluent in tests in 994 veterans. $^{3}$

Of the veterans recorded as being exposed to sulphur mustard, $74 \%$ of those in the analyses of cancer morbidity could be classified according to cumulative exposure. Veterans exposed to a total of $\geq 10.63 \mathrm{mg}$ of sulphur mustard were classified as having "high" exposures. ${ }^{3}$ Equivalent classifications were possible for $66 \%$ of veterans exposed to Lewisite and 75\% of those exposed to nitrogen mustard, the corresponding "high" exposure levels being $\geq 13.69 \mathrm{mg}$ and $\geq 23.73 \mathrm{mg}$, respectively. ${ }^{3}$ For $93 \%$ of tests involving sulphur mustard, we could classify veterans according to the biological effect recorded, equivalent figures 
being 98\% for Lewisite and 83\% for nitrogen mustard. Veterans with a least one dermal vesicle or a necrosed area recorded after tests involving these vesicants were classified as having had an exposure with at least one "high" biological effect. The derivation of these groups, and of similar groups for nerve agent exposures, is described elsewhere. ${ }^{3}$ For chemicals other than vesicants or nerve agents, we collected information on the number of tests recorded.

\section{Statistical analysis}

All veterans included in the previously reported mortality analysis as alive and under follow-up on or after 1 January 1971 contributed to the analysis. The primary method involved comparing registration rates in Porton Down veterans with those of non-Porton Down veterans by calculating rate ratios. For each Porton Down veteran, we counted person years of follow-up from 1 January 1971 or the earliest subsequent date that they were first recorded as being included in a test. For non-Porton Down veterans, we counted person years from the date derived by adding to their enlistment date the time between enlistment and first attendance at Porton Down for the veteran for whom they had been selected. For each specific cancer site or type, person years stopped at the earliest of date of registration of the first cancer, death, loss to followup, or 31 December 2004. For veterans lost to followup, person years stopped at the last date they were known to be alive (such as date of emigration or discharge from the services). When we compared rates in Porton Down and non-Porton Down veterans we included cancers identified only from the death certificate. For cancers identified in this way, we used the date of death as the date of cancer registration.

Rate ratios were estimated for all neoplasms combined and according to type (malignant, in situ, benign, uncertain or unknown behaviour). For malignant neoplasms, we also estimated rate ratios separately for 16 predetermined cancer sites or types. Veterans with more than one cancer of the same site or type had only the first cancer counted while those with cancers registered for two or more different types (such as primary cancers of skin and bladder) contributed a cancer to each. We calculated person years separately for each cancer site or type stratified according to 15 five year age groups $(15-19,20-25$, etc, to $\geq 85)$ and five year calendar periods (1971-4, 1975-9, etc, to 2000-4). All rate ratios were adjusted for age group and calendar period and estimated with 95\% confidence intervals, and $\mathrm{P}$ values calculated, with the Mantel-Haenszel method. ${ }^{7}$ When the number of cancers expected in either group of veterans was less than 10, we estimated adjusted rate ratios and tested for significance by fitting exact conditional Poisson regression models to the stratified data. $^{8}$

We also compared rates of cancer in each group of veterans with rates in England and Wales, using only

Table 3 | Rate ratios (95\% confidence intervals) for selected cancer sites and types in Porton Down veterans relative to non-Porton Down veterans, unadjusted and adjusted for age group and calendar period

\begin{tabular}{|c|c|c|c|c|}
\hline \multirow[b]{2}{*}{ Cancer site/type (ICD-10 code) } & \multicolumn{2}{|c|}{ No of cases } & \multicolumn{2}{|c|}{ Rate ratio } \\
\hline & $\begin{array}{l}\text { Porton Down } \\
\text { veterans }\end{array}$ & $\begin{array}{l}\text { Non-Porton Down } \\
\text { veterans }\end{array}$ & Unadjusted & $\begin{array}{l}\text { Adjusted } \\
(95 \% \mathrm{Cl})\end{array}$ \\
\hline Any malignant neoplasm (C00-C97) & 3114 & 3140 & 0.96 & $0.99(0.94$ to 1.04$)$ \\
\hline Upper aerodigestive (C00-C14, C30-C32) & 132 & 117 & 1.10 & $1.11(0.87$ to 1.43$)$ \\
\hline Oesophagus (C15) & 103 & 115 & 0.87 & $0.89(0.68$ to 1.16$)$ \\
\hline Stomach (C16) & 189 & 170 & 1.08 & $1.12(0.91$ to 1.38$)$ \\
\hline Intestine and rectum (C17-C20) & 364 & 392 & 0.90 & $0.93(0.81$ to 1.07$)$ \\
\hline Pancreas (C25) & 89 & 91 & 0.95 & $0.98(0.73$ to 1.31$)$ \\
\hline Trachea, bronchus, and lung $(\mathrm{C} 33, \mathrm{C} 34)$ & 851 & 782 & 1.06 & 1.09 (0.99 to 1.20$)$ \\
\hline Melanoma of skin (C43) & 60 & 50 & 1.17 & $1.19(0.82$ to 1.74$)$ \\
\hline Other skin (C44) & 436 & 496 & 0.86 & $0.87^{*}(0.77$ to 0.99$)$ \\
\hline Prostate (C61) & 381 & 422 & 0.88 & $0.92(0.80$ to 1.05$)$ \\
\hline Bladder (C67) & 193 & 202 & 0.93 & $0.97(0.79$ to 1.18$)$ \\
\hline Other urinary tract $(\mathrm{C} 64-\mathrm{C} 66, \mathrm{C} 68)$ & 65 & 85 & 0.75 & $0.76(0.55$ to 1.04$)$ \\
\hline Brain and other central nervous system $(C 71, C 72)$ & 56 & 66 & 0.83 & $0.83(0.58$ to 1.19$)$ \\
\hline All leukaemias (C91-C95) & 74 & 84 & 0.86 & $0.89(0.65$ to 1.21$)$ \\
\hline Other lymphatic and haematopoietic (C81-C90, C96) & 139 & 126 & 1.08 & 1.09 (0.86 to 1.39$)$ \\
\hline All other primary malignant neoplasms $†$ & 182 & 148 & 1.20 & $1.22(0.99$ to 1.52$)$ \\
\hline III defined, secondary, or unspecified malignant neoplasms (C76-C80) & 975 & 878 & 1.08 & $1.12^{*}(1.02$ to 1.22$)$ \\
\hline Any in situ neoplasm (D00-D09) & 93 & 64 & 1.42 & $1.45^{*}(1.06$ to 2.00$)$ \\
\hline Any benign neoplasm (D10-D36) & 31 & 31 & 0.98 & 0.99 (0.60 to 1.63$)$ \\
\hline Any neoplasm of uncertain or unknown behaviour (D37-D48) & 126 & 95 & 1.29 & $1.32 *(1.01$ to 1.73$)$ \\
\hline Any neoplasm (C00-C97, D00-D48) & 3288 & $3282 \ddagger$ & 0.97 & $1.00(0.95$ to 1.05$)$ \\
\hline
\end{tabular}

†C21-24, C26-C29, C37-C41, C45-C50, C60, C62, C63, C69, C70, C73-C75, C97.

‡Excludes neoplasms for four veterans for whom person years could not be calculated. 


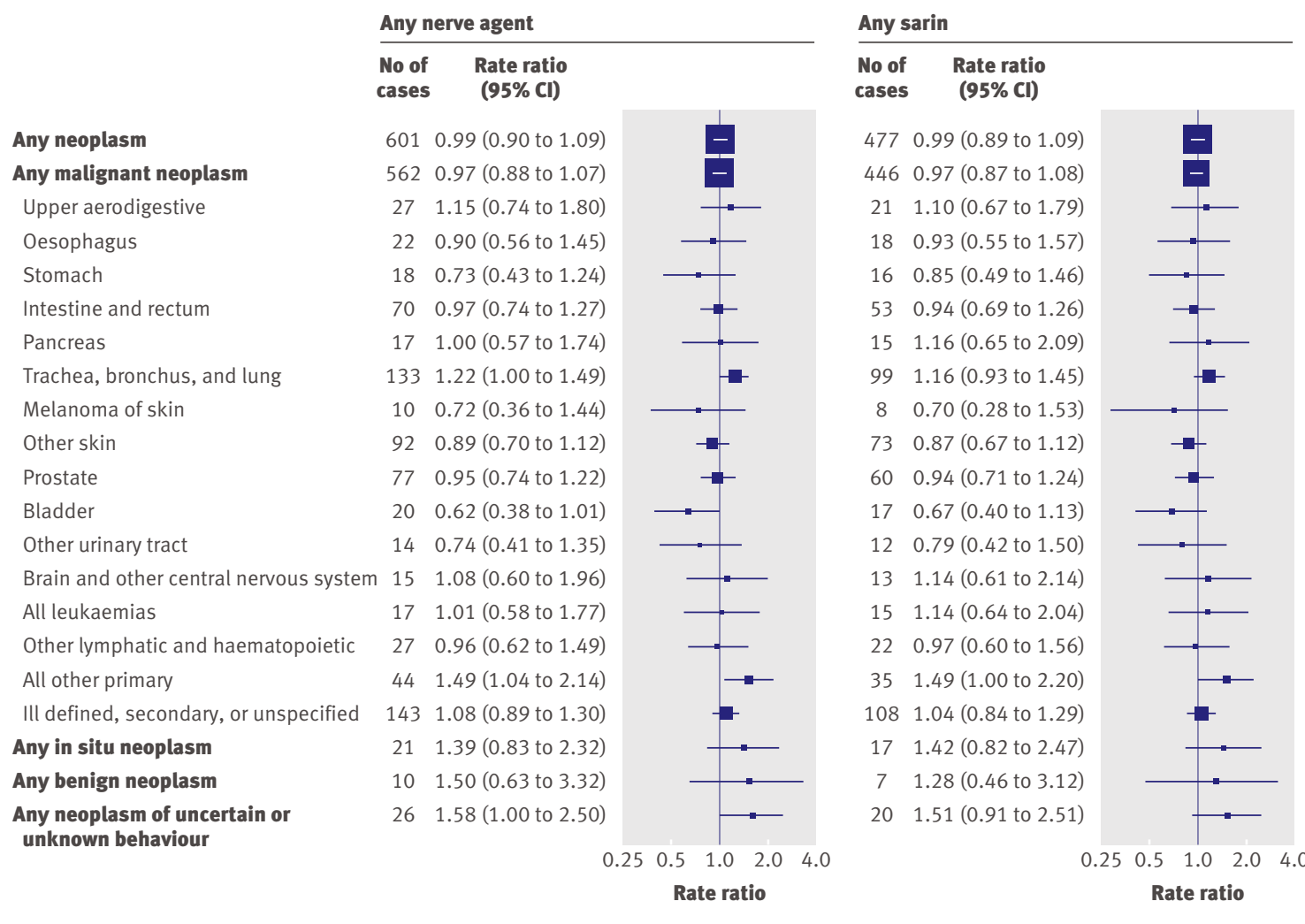

Fig $2 \mid$ Rate ratios for selected cancer sites or types in Porton Down veterans included in tests involving nerve agents relative to all non-Porton Down veterans, adjusted for age group and calendar period. Rate ratio estimates are represented by box with size inversely proportional to variance. Vertical dotted line shows the estimate for any neoplasm

those cancers notified from registrations. We counted person years from the same date as that used for rate ratio calculations but stopped at the date when the veteran was last known to be alive in the UK. We stratified person years of follow-up according to 15 five year age groups $(15-19,20-24$, etc, to $\geq 85)$ and by single calendar year (from 1941 to 2004). Expected registrations were calculated by multiplying the person years for each five year age group and single calendar year by the corresponding registration rates for England and Wales. Standardised registration ratios were estimated from the ratio of observed to expected registrations. We obtained 95\% confidence intervals and $\mathrm{P}$ values using the normal approximation to the Poisson distribution. $^{8}$

Analyses reported here relate to 17013 Porton Down veterans, and 16520 non-Porton Down veterans, all of whom were included in mortality analyses. ${ }^{4}$ Updating of databases after the mortality analysis removed two Porton Down veterans and four nonPorton Down veterans from the analysis but added three non-Porton Down veterans. All analyses were performed with Stata 10 (www.stata.com). All tests of significance were two sided.

\section{RESULTS}

Of the veterans included in the mortality analysis, 93\% (17013/18276) of Porton Down veterans and 94\% (16520/17 600) of non-Porton Down veterans contributed data to analyses on cancer morbidity. Of those excluded from analyses, in over $60 \%$ of Porton Down (796/1263) and non-Porton Down veterans $(703 / 1,080)$ this was because they had died between 1941 and 1970. Service at enlistment and other characteristics were similar to that of non-Porton Down veterans (table 1). As in the mortality study, Porton Down veterans had a longer total duration of military service. The distribution of Porton Down veterans according to frequency, calendar period, and type of chemical test was also similar to that reported previously (table 2).

The number of men with one or more cancer registrations was 3029 in Porton Down veterans and 3015 in non-Porton Down veterans. We identified a further 530 veterans with cancer from death certificates (259 and 271). The total number of cancers recorded in each group was 3457 and 3380, respectively. The percentage with two or more registrations was slightly larger in Porton Down than non-Porton Down veterans: $12.3 \%(374 / 3029) v 10.6 \%(320 / 3015)$.

Overall, rates for all neoplasms were the same in both groups of veterans (rate ratio 1.00, 95\% confidence interval 0.95 to 1.05 ) as were those for all malignant neoplasms $(0.99,0.94$ to 1.04$)$ (table 3). Porton Down veterans had higher rates of ill defined, secondary, or unspecified malignant neoplasms (1.12, 1.02 to 1.22), in situ neoplasms $(1.45,1.06$ to 2.00$)$, and those of uncertain or unknown behaviour $(1.32,1.01$ to 1.73$)$ 
Table 4 | Rate ratios (95\% confidence intervals) for selected cancer sites/types (ICD-10) for Porton Down veterans with high recorded levels of exposure to specific chemicals relative to non-Porton Down veterans, adjusted for age group and calendar period

\begin{tabular}{|c|c|c|}
\hline Chemical and indicator of high exposure level & No of cases & Adjusted rate ratio $(95 \% \mathrm{Cl})$ \\
\hline \multicolumn{3}{|l|}{ Sulphur mustard } \\
\hline \multicolumn{3}{|l|}{ Dermal $\geq 10.63$ mg: } \\
\hline Upper aerodigestive (C00-C14, C30-C32) & 26 & $0.91(0.60$ to 1.40$)$ \\
\hline Trachea, bronchus, and lung (C33, C34) & 207 & $0.98(0.84$ to 1.15$)$ \\
\hline \multicolumn{3}{|l|}{ Dermal vesicle: } \\
\hline Upper aerodigestive (C00-C14, C30-C32) & 38 & $1.28(0.88$ to 1.86$)$ \\
\hline Trachea, bronchus, and lung (C33, C34) & 266 & $1.10(0.95$ to 1.27$)$ \\
\hline \multicolumn{3}{|l|}{ Lewisite } \\
\hline \multicolumn{3}{|l|}{ Dermal $\geq 13.69$ mg: } \\
\hline Trachea, bronchus, and lung (C33, C34) & 31 & $1.22(0.85$ to 1.75$)$ \\
\hline Other skin (C44) & 11 & 1.17 (0.58 to 1.94$)$ \\
\hline \multicolumn{3}{|l|}{ Dermal vesicle: } \\
\hline Trachea, bronchus, and lung (C33, C34) & 76 & $1.26(0.99$ to 1.59$)$ \\
\hline Other skin (C44) & 21 & $0.85(0.55$ to 1.33$)$ \\
\hline \multicolumn{3}{|l|}{ Nitrogen mustard } \\
\hline \multicolumn{3}{|l|}{ Dermal $\geq 23.73$ mg: } \\
\hline Other skin (C44) & 17 & $1.59(0.97$ to 2.61$)$ \\
\hline All leukaemias (C91-C95) & 1 & $0.47(0.01$ to 2.78$)$ \\
\hline \multicolumn{3}{|l|}{ Dermal vesicle: } \\
\hline Other skin (C44) & 12 & $1.05(0.59$ to 1.87$)$ \\
\hline All leukaemias (C91-C95) & 0 & $0.00(0.00$ to 1.74$)$ \\
\hline \multicolumn{3}{|l|}{ CS (two or more tests) } \\
\hline Oesophagus (C15) & 5 & $2.73(0.84$ to 6.97$)$ \\
\hline \multicolumn{3}{|l|}{ Pralidoxime (two or more tests) } \\
\hline $\begin{array}{l}\text { All neoplasms of uncertain or unknown behaviour } \\
\text { (D37-D48) }\end{array}$ & 5 & $2.88(0.80$ to 8.42$)$ \\
\hline \multicolumn{3}{|l|}{ Atropine (two or more tests) } \\
\hline $\begin{array}{l}\text { All neoplasms of uncertain or unknown behaviour } \\
\text { (D37-D48) }\end{array}$ & 3 & $2.28(0.45$ to 7.26$)$ \\
\hline \multicolumn{3}{|l|}{ Benzene (two or more tests) } \\
\hline All leukaemias (C91-C95) & 7 & $1.44(0.55$ to 3.21$)$ \\
\hline
\end{tabular}

and lower rates of skin cancer other than melanoma $(0.87,0.77$ to 0.99$)$. Some neoplasms classified as in situ or of uncertain or unknown behaviour (16 in Porton Down and 10 in non-Porton Down veterans) were nonmelanoma skin cancers. When we combined these with malignant skin cancers other than melanoma, the rate ratio for this cancer site increased only slightly $(0.89$, 0.78 to 1.01$)$.

Rate ratios for all neoplasms and all malignant neoplasms were just below unity for veterans exposed to tests involving any vesicant, sulphur mustard, or nitrogen mustard and just above unity for Lewisite (fig 1). Veterans exposed to Lewisite had rates of cancer of the trachea, bronchus, and lung 25\% higher than non-Porton Down veterans $(1.25,1.05$ to $1.48, \mathrm{P}=0.01)$. Porton Down veterans exposed to tests involving any nerve agent, sarin, or any chemical other than nerve agents or vesicants had rate ratios for all neoplasms and all malignant neoplasms just below unity (figs 2 and 3). The rate of cancer of the oesophagus was raised in veterans exposed to $\mathrm{CS}(2.17,1.04$ to $4.52, \mathrm{P}=0.03)$.

Table 4 shows results for veterans classified as having had high levels of exposure or biological effect either for chemicals with previous evidence of carcinogenicity (such as sulphur mustard for cancers of the trachea, bronchus, and lung) or where rate ratios were raised in Porton Down veterans (such as for CS and oesophageal cancer). When we compared the resultant estimates of rate ratios to the results for all exposed Porton Down veterans, in nearly all cases the estimate obtained was lower or similar to that obtained for all veterans. The only instance where the estimate for the high exposure group was above the upper limit of the $95 \%$ confidence interval for all veterans was for skin cancers other than melanoma in relation to high dermal exposure to nitrogen mustard $(1.59,0.97$ to $2.61, v 1.13,0.82$ to 1.57$)$. For veterans with a dermal vesicle recorded (high biological effect), however, the rate ratio estimate was lower than that of all exposed veterans $(1.05,0.59$ to 1.87$)$.

When compared with cancer registration rates in England and Wales, rates in Porton Down veterans were 10\% lower for all neoplasms (standardised registration ratio $0.90,0.87$ to 0.93 ) and $6 \%$ lower for all malignant neoplasms $(0.94,0.91$ to 0.98$)$. Corresponding results for non-Porton Down veterans were $0.87(0.85$ to 0.90$)$ and 0.94 (0.90 to 0.97$)$, respectively.

\section{DISCUSSION}

Overall occurrence of cancer in veterans who took part in tests at Porton Down was similar to that of other veterans and lower than in the general population. These findings are in accord with their cancer mortality. ${ }^{4}$ We also found no evidence of an excess of any specific, clearly defined, cancer type or site in all Porton Down veterans combined. As expected, the similarity to our findings for mortality was particularly notable for highly fatal cancers such as those of the trachea, bronchus, and lung: the $9 \%$ higher rates of lung cancer morbidity in Porton Down veterans is identical to the excess reported for mortality. ${ }^{4}$ In the current study, we were particularly interested in cancers with a relatively good survival. There was no evidence to suggest rates of one of the commonest of thesemalignant skin cancers other than melanoma-were higher in Porton Down veterans, even after we reclassified neoplasms previously coded as in situ or of uncertain or unknown behaviour. Porton Down veterans did, however, experience increased rates of ill defined, secondary or unspecified malignant neoplasms, in situ neoplasms, and neoplasms of uncertain or unknown behaviour. Such findings are difficult to interpret in the absence of information on smoking habits and other risk factors for cancer.

We identified almost 500 different chemicals in the records at Porton Down for 1941-89. ${ }^{3}$ We focused on nine specific chemicals to which the largest numbers of veterans were exposed. Given the large number of outcomes and exposure groups, some of the associations found might be due to chance. Of the nine chemicals, sulphur mustard and benzene are known human carcinogens, while nitrogen mustard is a probable carcinogen. ${ }^{6}$ Of these, the chemical most often used in tests was sulphur mustard, a carcinogen known to affect the upper and lower respiratory tract. 


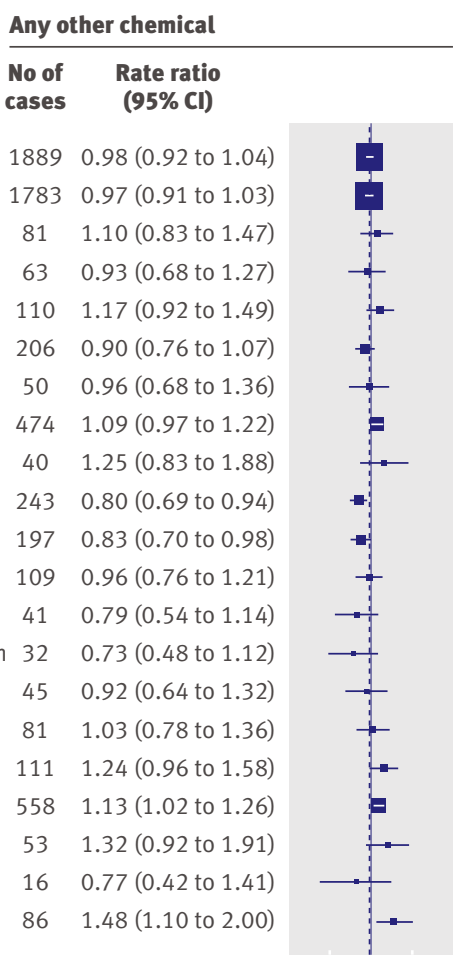

\section{Any neoplasm \\ Any malignant neoplasm}

Upper aerodigestive

Oesophagus

Stomach

Intestine and rectum

Pancreas

Trachea, bronchus, and lung

Melanoma of skin

Other skin

Prostate

Bladder

Other urinary tract

Brain and other central nervous system

All leukaemias

Other lymphatic and haematopoietic

All other primary

IIl defined, secondary, or unspecified

Any in situ neoplasm

Any benign neoplasm

Any neoplasm of uncertain or

unknown behaviour

\section{Any pralidoxime}

\section{Any neoplasm}

Any malignant neoplasm

Upper aerodigestive

Oesophagus

Stomach

Intestine and rectum

Pancreas

Trachea, bronchus, and lung

Melanoma of skin

Other skin

Prostate

Bladder

Other urinary tract

Brain and other central nervous system All leukaemias

Other lymphatic and haematopoietic

All other primary

Ill defined, secondary, or unspecified

Any in situ neoplasm

Any benign neoplasm

Any neoplasm of uncertain or

unknown behaviour

\begin{tabular}{lc} 
Any CS & \\
\hline $\begin{array}{l}\text { No of } \\
\text { Cases }\end{array}$ & $\begin{array}{c}\text { Rate ratio } \\
(95 \% \mathrm{Cl})\end{array}$
\end{tabular}

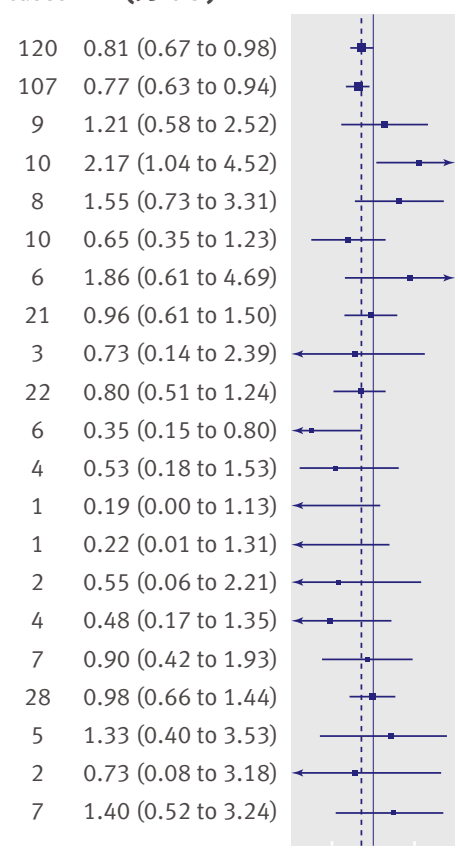

\section{Any atropine}

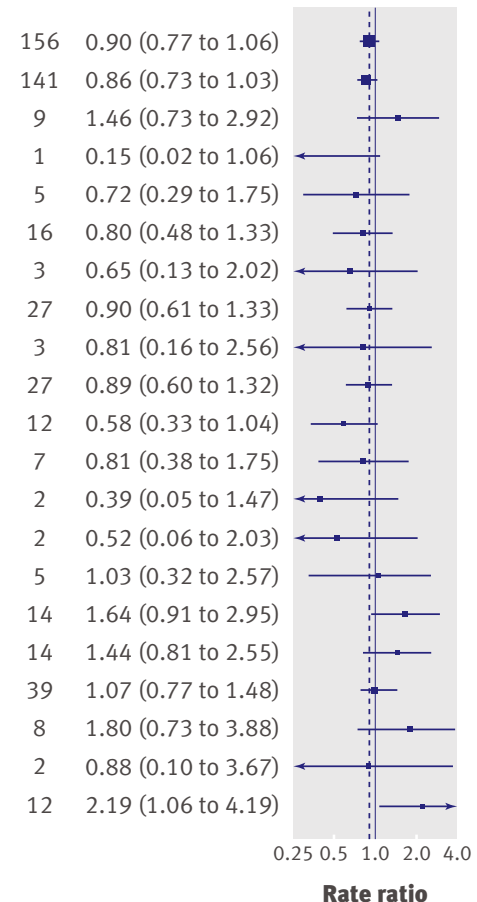

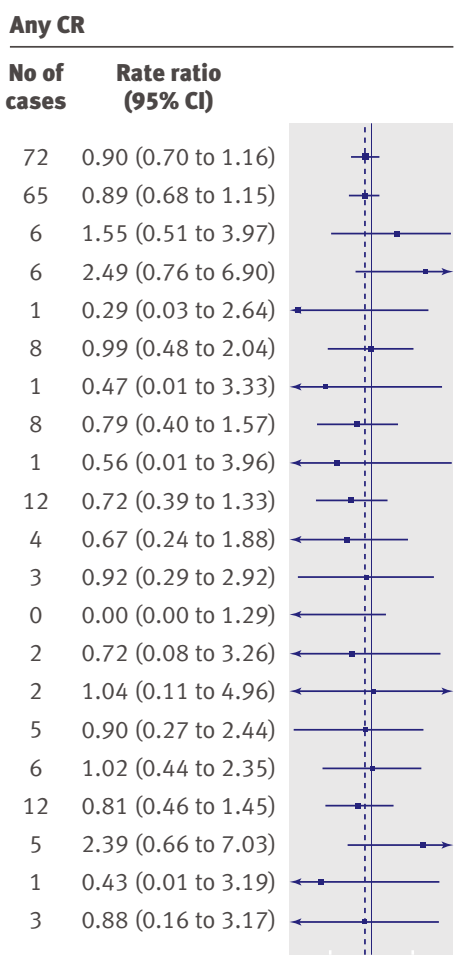

Any benzene

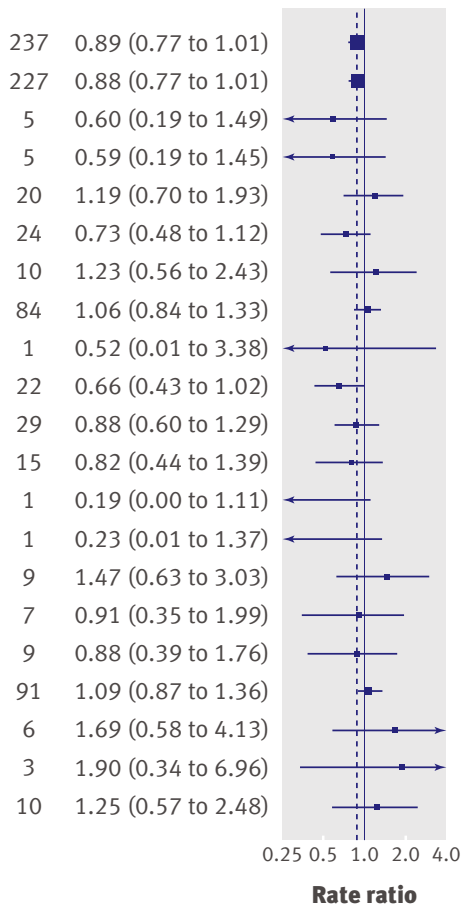

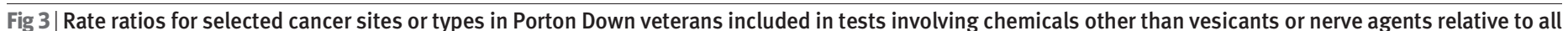

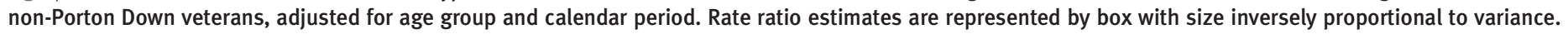
Vertical dotted line shows the estimate for any neoplasm

Over half of Porton Down veterans were included in tests involving this chemical but they experienced no increased cancer morbidity, either overall or for any specific cancer. This probably reflects the low cumulative exposures received, especially compared with those of manufacturing workers in whom excesses of upper and lower respiratory cancer have been reported. ${ }^{910}$ In addition, use of physical protective barriers (such as masks and clothing), which were recorded as used in over 30\% of tests involving vesicants, ${ }^{3}$ will have reduced the actual exposure of veterans to these chemicals. 


\section{WHAT IS ALREADY KNOWN ON THIS TOPIC}

Many tests in the Porton Down research programme into

chemical warfare agents involved known carcinogens

\section{WHAT THIS STUDY ADDS}

Overall cancer morbidity was no higher in military personnel who had been included in tests at Porton Down than in those who had not been included or in the general population

Despite it being a known human carcinogen, there was no evidence of an overall excess of cancer in veterans exposed to benzene. Previous epidemiological evidence indicates an association between occupational exposure to benzene and leukaemia. ${ }^{6}$ Although the rate ratio for leukaemia was above unity, the confidence interval was wide and the rate ratio did not increase when we restricted analysis to veterans with two or more tests. The increased strength of association with skin cancer other than melanoma in veterans recorded to have high exposure to nitrogen mustard is noteworthy, given previous evidence that this chemical is a human carcinogen. ${ }^{6}$ This needs to be qualified, however, by the absence of an increase in those in whom the biological effect was high.

Although arsenic and arsenic compounds are human carcinogens, ${ }^{6}$ and Lewisite is an organic arsenic compound, there have been no previous epidemiological studies of the carcinogenicity of this specific chemical. ${ }^{11}$ While there was no evidence of an overall excess of cancer in Porton Down veterans exposed to Lewisite, there was an excess of lung cancer, which was also present in our previous mortality analyses. ${ }^{4}$ The lack of association with increasing exposure or effect levels for this chemical, together with the lack of data on a known key confounding factor (smoking), make it difficult to attribute this excess to tests at Porton Down and it might be a chance finding.

For the other chemicals examined, there were no clear associations between any specific defined cancer type or site with sarin, pralidoxime, or atropine. For CS, while the overall cancer occurrence was lower than in non-Porton Down veterans, it was raised for cancer of the oesophagus, particularly in those who had two or more tests. A similar excess was seen in veterans exposed to $\mathrm{CR}$, the other lachrymator included in our analyses.

In summary, the overall rates of cancer morbidity in Porton Down veterans were not raised relative to other veterans or the general population. The excesses of ill defined, secondary or unspecified malignant neoplasms, in situ neoplasms, and neoplasms of uncertain or unknown behaviour were seen across several of the chemical exposure groups analysed and are difficult to interpret.

We thank the many people and organisations who contributed to this research project and full acknowledgements are listed elsewhere. ${ }^{4}$ In particular, we thank the MRC Liaison Group established for this study, the Porton Down Veterans Support Group, the MoD Veterans Policy Unit, the Defence Science and Technology Laboratory at Porton Down, the National Health Service Central Register, the General Register Office for Scotland the Office for National Statistics, and the individual cancer registries in England, Wales, Scotland, and Northern Ireland. We especially thank Bianca De Stavola for her work on exact analytical methods, David Cox and Michael Hills for their valuable guidance. The figures were originally plotted by Adrian Goodill, Cancer Epidemiology Unit, University of Oxford. Contributors: KMV and LMC jointly led the study and are its guarantors. Al authors participated in the study design, plan of analysis, interpretation of the results, and drafting of the paper. LL carried out the statistical analyses, with contributions from CB.

Funding: This study was funded by the MRC with funds provided to it by the MoD. Additional funds were provided by the Department of Public Health and Nuffield College, University of Oxford. The MRC set up a liaison group to oversee the progress of the study. The MoD had no role in study design, analysis, and interpretation of data. The MoD facilitated access to its archives but had no role in deciding which data were abstracted. The MoD was sent a copy of the paper for factual comment but had no role in writing the paper or in the decision to submit for publication. The Universities of Oxford and London are independent of both the MRC and the MoD.

Competing interests: None declared.

Ethical approval: The study was approved by the south east multicentre research ethics committee, the Defence Medical Services clinical research committee, and the Patient Information Advisory Group.

1 Ministry of Defence. Historical survey of the Porton Down service volunteer programme 1939-1989. London: Ministry of Defence, 2006.

2 Evans R. Gassed. London: House of Stratus, 2000.

3 Keegan TJ, Walker SAS, Brooks C, Langdon T, Linsell L, Maconochie NES, et al. Exposures recorded for participants in the UK chemical warfare agents human research programme, 1941-1989. Ann Occup Hyg 2009;53:83-97.

4 Venables KM, Brooks C, Linsell L, Keegan TJ, Langdon T, Fletcher T, et al. Mortality in British military participants in human experimenta research into chemical warfare agents at Porton Down: cohort study. BMJ 2009;b613.

5 Keegan TJ, Nieuwenhuijsen MJ, Fletcher T, Brooks C, Doyle P, Maconochie NES, et al. Reconstructing exposures from the UK Chemical Warfare Agent Human Research Programme. Ann Occup Hyg 2007;51:441-50.

6 International Agency for Research on Cancer. IARC monographs on the evaluation of carcinogenic risks to humans. Lyon: IARC. http:// monographs.iarc.fr/.

7 Mantel N, Haenszel W. Statistical aspects of the analysis of data from retrospective studies. J Natl Cancer Inst 1959;22:719-48.

8 Clayton D, Hills M. Statistical models in epidemiology. Oxford: Oxford University Press, 1993.

9 Easton DF, Peto J, Doll R. Cancers of the respiratory tract in mustard gas workers. Br J Ind Med 1988;45:652-9.

10 Wada S, Miyanishi M, Nishimoto Y, Kambe S, Miller RW. Mustard gas as a cause of respiratory neoplasia in man. Lancet 1968;i:1161-3.

11 Committee to survey the health effects of mustard gas and Lewisite. Pechura CM, Rall DP, eds. Veterans at risk: the health effects of mustard gas and Lewisite. Washington, DC: National Academy Press, 1993.

Accepted: 5 December 2008 